\title{
EDITORIAL \\ NUEVA DIRECCIÓN DE LA REVISTA Y NUEVO EQUIPO DE REDACCIÓN
}

La Revista de Derecho de la Universidad Católica del Norte entera 24 ańos de vida ininterrumpida, desde que iniciara su camino el año 1994, a la par, casi, con la creación de las Escuelas de Derecho fundadas en 1993 (Antofagasta-Coquimbo).

Seguramente 24 años es un tiempo considerable en el concierto de publicaciones jurídicas de carácter científico vinculadas a centros universitarios. A lo largo de aquel se han conseguido cosas relevantes, como ha sido, por ejemplo, la incorporación a índices y bases de datos sobre publicaciones períodicas muy importantes, lo que ha sido posible gracias al reconocimiento general de su calidad en cuanto medio de difusión científico, circunstancias que ponen a nuestra Revista en un grupo de avanzada en la materia.

Estas son las razones por las cuales he asumido con entusiasmo el nombramiento en la dirección de nuestra Revista desde marzo de este año. Agradezco a la Decana de la Facultad, Dra. Carolina Salas Salazar, por esta designación, y al Consejo de Facultad, que ratificó la decisión de aquella. Espero poder cumplir el encargo fundamental que se me ha formulado, y que no es otro que mantener el empeño en la búsqueda de excelencia académica en la difusión de los resultados de la investigación jurídica. Y como consecuencia de aquello conseguir en un plazo razonable la incorporación de nuestra Revista a nuevos índices científicos.

La decanatura, a instancia del suscrito, ha estimado oportuno renovar para esta etapa el equipo de redacción que colabora en la edición de nuestra publicación. Así, ha procedido al nombramiento de un nuevo Secretario de Redacción, recayendo tal responsabilidad en el profesor Dr. Andrea Perin (de la Escuela de Antofagasta), y también al nombramiento de nuevos miembros del Consejo de Redacción en las vacantes disponibles, señalando en esa responsabilidad a los profesores Dr. Álvaro Pérez Ragone y Dra. Daniela Jarufe Contreras (ambos de la Escuela de Antofagasta), y al profesor Dr. Cristián Delpiano Lira (de la Escuela de Coquimbo).

A nombre de quienes asumimos las responsabilidades indicadas, manifiesto el compromiso permanente para continuar trabajando estrechamente con todos los investigadores en los diversos campos de las ciencias jurídicas, y mantener -asimismo- la contribución que la Revista ha venido desarrollando en el seno de las instancias institucionales que aglutinan a los medios de difusión científica existentes en el país. 
Apunto ahora brevemente, en lo tocante a este número de la Revista, que en este se ofrecen muy buenos trabajos jurídicos, los cuales abarcan las principales ramas del Derecho. En la sección de estudios se encontrarán seis artículos, tres de ellos frutos de proyectos de investigación Fondecyt, y que cubren diversos aspectos del Derecho privado, del Derecho procesal y del Derecho público.

En la sección destinada a ensayos se suman un trabajo de Derecho penal y otro sobre una especialidad del Derecho internacional. En la sección de jurisprudencia, cabe resaltar el comentario de una sentencia penal emanada de un Tribunal de la jurisdicción de La Serena. En fin, en la de comentarios bibliográficos se incluye una recensión a un estudio monográfico sobre una materia que hace parte de lo que se denomina el orden público económico.

Como podrá advertir el lector al analizar el presente número, los contenidos y secciones comprendidos en el mismo dan cuenta del equilibrio temático que debe poseer una revista general de Derecho, tanto como del esfuerzo por poner a su disposición los mejores resultados de la investigación jurídica que se produce en nuestro medio.

Prof. Dr. Carlos del Río FerretTi

DIRECTOR 